\title{
0 significado da dança circular no imaginário da pessoa idosa
}

\author{
The meaning of circular dance in the imagination of the older people
}

\author{
Kelly Maciel Silva' ${ }^{1}$ \\ Rosane Gonçalves Nitschke ${ }^{2}$ (D) \\ Michelle Kuntz Durand ${ }^{3} \mathbb{D}$ \\ Ivonete Teresinha Schülter Buss Heidemann² ${ }^{\mathbb{D}}$ \\ Adriana Dutra Tholl ${ }^{4}$ (D) \\ Aline Megumi Arakawa Belaunde 5
}

\section{Resumo}

Objetivo: compreender o significado da dança circular no imaginário da pessoa idosa em seu quotidiano. Método: estudo interpretativo, de natureza qualitativa, fundamentado na Sociologia Compreensiva e do Quotidiano de Michel Maffesoli. Os dados foram coletados por meio de entrevista e observação participante, com 17 idosas praticantes de dança circular em Rodas nas Unidades Primárias de Saúde do Sul Brasil. Os dados foram analisados por meio dos preceitos de análise Shatzman e Strauss, fazendo emergir duas categorias temáticas: Atribuindo significado à dança circular e sentindo por meio da dança circular. Resultados: Os participantes apontam que a dança circular, no imaginário da pessoa idosa, apresenta-se inclusiva e acolhedora, favorecendo a sensação de pertencimento e união entre todos, sem perder a sua individualidade e a do outro que compartilha. Para participar da dança é necessário estar centrada em si, no momento vivido, buscando não dispersar do momento vívido. Considerações finais: a dança circular como expressão da vida cotidiana é um espaço de trocas, de presença, do lúdico, do viver coletivo ligado por laços emocionais e pelo afeto que fortalece os laços e ressignifica positivamente o viver.

Palavras-chave: Saúde do Idoso. Dança. Promoção da Saúde. Atividades Cotidianas.

Prefeitura Municipal de Florianópolis, Secretaria Municipal de Saúde de Florianópolis. Florianópolis, Santa Catarina, Brasil.

2 Universidade Federal de Santa Catarina, Departamento de Enfermagem, Programa de Pós-Graduação de Enfermagem. Florianópolis, Santa Catarina, Brasil.

3 Universidade Federal de Santa Catarina, Departamento de Enfermagem. Florianópolis, Santa Catarina, Brasil.

4 Universidade Federal de Santa Catarina, Departamento de Enfermagem, Programa de Pós-Graduação em Gestão do Cuidado em Enfermagem (Modalidade Profissional). Florianópolis, Santa Catarina, Brasil.

5 Universidade Federal de Santa Catarina, Departamento de Fonoaudiologia. Florianópolis, Santa Catarina, Brasil.

Financiamento da pesquisa: Secretaria de Educação do Governo do Estado de Santa Catarina por meio de concessão de Bolsa de Doutorado através do Programa de Bolsas UNIEDU/FUMDES, chamada pública $\mathrm{n}^{\circ} 08 / \mathrm{SED}$ de 20/03/2014.

Os autores declaram não haver conflito na concepção deste trabalho. 


\section{Abstract}

Objective: To understand the meaning of circular dance in the imagination of older people in their daily lives. Method: interpretative study, qualitative in nature, based on Michel Maffesoli's Comprehensive and Everyday Sociology. Data were collected through interviews and participant observation, with 17 older women practicing circular dance in Rodas (circular dance groups) in the Primary Health Units of Southern Brazil. Data were analyzed using the Shatzman and Strauss analysis precepts, bringing out two thematic categories: Attributing meaning to circular dance and feeling through circular dance. Results: Participants point out that circular dance, in the older person's imagination, is inclusive and welcoming, favoring the feeling of belonging and unity among everyone, without losing their individuality and that of the other who shares. To participate in the dance, it is necessary to be centered on oneself, in the moment, seeking not to stray from the vivid moment. Final considerations: circular dance as an expression of everyday life is a space for exchange, presence, play, collective living linked by emotional ties and affection that strengthens ties and positively resignifies living.
Keywords: Health of the Elderly. Dance. Health Promotion. Activities of Daily Living.

\section{INTRODUÇÃO}

A Dança Circular (DC) é uma prática de dança realizada em roda, tradicional e contemporânea, originária da tradição folclórica de diferentes culturas. São danças feitas em círculo com o propósito de dançar junto, favorecendo a aprendizagem e interconexão harmoniosa entre os participantes que começam a internalizar os movimentos, liberar a mente, o coração, o corpo e o espírito. Por meio do ritmo, da melodia e dos movimentos delicados ou vigorosos os integrantes da roda são estimulados a respeitar, aceitar e honrar as diversidades ${ }^{1,2}$.

Para a prática de DC não é necessária experiência anterior, nem habilidades específicas para desenvolver os movimentos. As rodas são conduzidas por um focalizador, que é um integrante do grupo que passa aos demais a coreografia de cada dança, sua história, a música, as intenções e os símbolos ${ }^{3,4}$.

A participação de idosos em grupos de DC constitui-se uma alternativa para promover a melhoria da sua qualidade de vida. Por meio dessa dança ocorre a união entre as pessoas, o movimento do círculo e das mãos que estimulam expressar os sentimentos de confiança, igualdade, apoio mútuo, fazendo com que cada um compreenda sua importância no tempo e espaço ${ }^{5}$.

Recentemente, a DC foi integrada à oferta de Práticas Integrativas e Complementares em Saúde
(PICS), por meio da Portaria n ${ }^{\circ} 849 / 2017$, que amplia os procedimentos oferecidos no Sistema Único de Saúde (SUS) ${ }^{2}$. Fato que reitera o recurso terapêutico desta atividade e possibilita a construção de um novo paradigma no contexto da saúde pública do país.

As terapias integrativas e complementares surgem como um reforço ao pressuposto da integralidade na atenção à saúde, visualizando o usuário de uma maneira holística, diferenciando-se das terapias convencionais que dão maior ênfase ao modelo biomédico, curativista e centrado na doença ${ }^{6}$.

A implementação das PICs está em consonância com os princípios do SUS, tais como integralidade, universalidade e equidade. Pode ser considerada uma importante estratégia para a construção de um modelo de atenção que estimule e busque formas de se relacionar humanizadas, com respeito às singularidades e subjetividades dos sujeitos?.

A Política Nacional de Promoção da Saúde (PNaPS) aponta em um de seus objetivos a necessidade de valorizar os saberes tradicionais e as práticas integrativas e complementares, reconhecendo essas ações como importantes para a Promoção da Saúde da população ${ }^{8}$.

A DC pode ser considerada uma prática que contribui no campo de ação da Promoção da Saúde. Esta atividade está articulada com os cinco campos descritos na Carta de Ottawa: a criação 
de ambientes favoráveis, o desenvolvimento de habilidades pessoais, o reforço da ação comunitária, a reorientação dos serviços de saúde e a criação de políticas públicas saudáveis?.

A prática da DC é aberta a todas as idades, porém, no quotidiano dos serviços de saúde, percebe-se uma procura maior por pessoas idosas. O processo de transição demográfica e epidemiológica contribui para que os idosos sejam percebidos como o grupo populacional que mais frequenta os Centros de Saúde. Porém, muito do cuidado ofertado a essa população é realizado na lógica do modelo biomédico de atendimento, centrado em uma proposta curativista, que focaliza a doença e não o ser humano, destoando da proposta de Promoção da Saúde ${ }^{10}$.

Os benefícios da dança na terceira idade sinalizam que a dança é uma atividade física positivamente associada à melhoria da saúde e qualidade de vida dos idosos, evidenciando benefícios nos aspectos físicos, sociais e emocionais ${ }^{11}$. Dentre as atividades de Promoção da Saúde que têm sido desenvolvidas para os idosos no SUS, é relevante conhecer sobre os significados e o imaginário da prática da DC e como a realização desta atividade repercute no quotidiano das pessoas idosas. Entende-se o quotidiano como a maneira de viver dos seres humanos que se revela nas interações, crenças, valores, significados, símbolos e imagens que vão desenhando seu processo de viver, num movimento de ser saudável e adoecer, pontuando seu ciclo vital ${ }^{12}$.

É no quotidiano que as imagens e os símbolos se apresentam, integrando o imaginário. Neste estudo, o imaginário é entendido como um mundo de significados, de ideias, de fantasias, de evocação de figuras já percebidas ou não percebidas, de crenças, de valores, onde o ser humano está mergulhado. Enfim, o imaginário, é um mundo de significados, que são incorporados a imagens ${ }^{13}$.

Tem-se como objetivo compreender o significado da DC no imaginário da pessoa idosa em seu quotidiano, bem como propor novas possibilidades de cuidado, na perspectiva de melhora da qualidade de vida das pessoas que envelhecem, colaborando com a Promoção da Saúde desta população.

\section{MÉTODO}

Trata-se de um estudo interpretativo, de natureza qualitativa, fundamentado na Sociologia Compreensiva e do Quotidiano, trazendo as noções e os Pressupostos Teóricos da Sensibilidade (crítica ao dualismo esquemático, a forma, sensibilidade relativista, pesquisa estilística, pensamento libertário) propostos por Michel Maffesoli. A possibilidade que este referencial proporciona para a compreensão da experiência humana, envolve significados, símbolos, imagens e o imaginário, bem como a razão sensível ${ }^{12}$.

O estudo foi realizado em três Unidades Básicas de Saúde (UBS) de um município do Sul do Brasil, selecionando um tamanho de amostra dos entrevistados capaz de atender a compreensão do objeto estudo. A escolha das Unidades foi feita de forma intencional, sendo selecionadas aquelas que ofertavam Rodas de DC à população, sendo considerado como critério de inclusão estes centros de saúde. Integraram esse estudo 17 pessoas idosas que praticavam DC regularmente, no mínimo uma vez na semana, há pelo menos três meses.

Destaca-se que todas as pessoas com idade maior ou igual a 60 anos, praticantes de DC, no cenário estudado, foram convidadas e aceitaram de maneira voluntária fazer parte da pesquisa. Por meio de entrevista em profundidade e observação participante, a coleta de dados ocorreu no período de setembro de 2016 a março de 2017, em horário e local agendados de acordo com a preferência de cada participante. As entrevistas foram gravadas digitalmente e, posteriormente, transcritas e tiveram duração média de 50 minutos, sendo guiadas por perguntas norteadoras acerca do quotidiano dos participantes, o significado da DC e aspectos relacionados à saúde dos mesmos.

A observação participante foi utilizada com caráter complementar às entrevistas, seguindo um roteiro que contemplava elementos a serem observados como o número de participantes, a interação entre eles, bem como as reações verbais e não verbais após cada dança. Ao total foram realizadas 10 sessões de observações, em dias alternados, nas três Rodas, com duração média de 
1 hora e 40 minutos cada. Utilizou-se um Diário de Campo envolvendo Notas de Interação, Notas Metodológicas, Notas Teóricas e Notas Reflexivas para o registro das informações.

Como método de análise de dados, utilizou-se o modelo sugerido por Shatzman e Strauss: análise preliminar, ordenação, ligações-chave, codificação e categorização ${ }^{14}$. Através de leituras e releituras dos textos gerados das transcrições das entrevistas e das observações, destacaram-se as falas significativas que deram origem ao processo de codificação inicial. Em seguimento, depurou-se o processo de codificação, por meio da identificação das classes e suas ligações, que guiou a elaboração das categorias temáticas.

O estudo foi aprovado pelo Comitê de Ética em Pesquisa com Seres Humanos sob o no 1.744 .314 , e respeitou os princípios éticos previstos na Resolução n. 466/12 do Conselho Nacional de Saúde ${ }^{15}$. Os dados somente foram coletados com a autorização dos participantes por meio de assinatura do Termo de Consentimento Livre e Esclarecido, após leitura e explicação.

Para garantia do anonimato dos participantes seus nomes foram substituídos pelos seguintes codinomes, no caso das pessoas idosas: Inspiração, Confiança, Propósito, Diversão, Força, Entrega, Contentamento, Espontaneidade, Equilíbrio, Bondade, Beleza, Fé, Transformação, Simplicidade, Apoio, Perdão e Celebração.

\section{RESULTADOS}

Os participantes tinham idade entre 64 e 82 anos, com uma média de 65 anos sendo 16 mulheres e um homem. Referentes à escolaridade, nove possuíam Ensino Fundamental Incompleto; três, Ensino Fundamental Completo; três, Ensino Médio; e duas, Ensino Superior. No que se refere ao estado civil, 13 participantes eram casadas e quatro, viúvas, todas referiram ter tido filhos, cujo número variou entre dois e 14, com média de 4,6. Considerando a ocupação, oito denominaram-se como donas de casa, oito estavam aposentadas e uma era artesã.

O significado da DC no imaginário da pessoa idosa é revelado em duas categorias apresentadas a seguir: Atribuindo Significado à DC e Sentindo por meio da DC.

\section{Atribuindo Significado à Dança Circular}

As pessoas idosas, ao vivenciarem a experiência de dançar de mãos dadas em círculo, simbolizam a união entre os participantes e a posição de igualdade que o centro lhes confere. Neste aspecto, destacaram a percepção de que a DC é para todos, sem distinção, um movimento que favorece o convívio com a diversidade e diferenças.

\footnotetext{
"Na DC percebo a união entre as pessoas. Ali somos todos iguais, não tem rico, não tem pobre. Percebo todo mundo se tratando muito bem, principalmente as professoras, que dão muita atenção, muitas vezes é disso que os idosos precisam." (Força).
}

Percebe-se que se desprende das falas o caráter inclusivo e acolhedor que a DC proporciona. Emerge dos significados que a presença do outro é fundamental para garantir a sensação de pertencimento ao grupo.

"Além de dançar eu gosto muito de pessoas, de estar no meio de pessoas, de participar de grupos" (Diversão).

"Parece que a gente juntou o mesmo grupo de almas" (Equilíbrio).

"Eu gosto de estar com mais gente, não gosto de solidão, de ficar sozinha em casa” (Beleza).

A DC é uma atividade física diferenciada por proporcionar maior interação entre as pessoas, resgatando o querer fazer e não o ter que fazer.

"Eu tinha necessidade de fazer um exercício, mas ginástica eu não queria fazer. A dança é mais gostosa, tem as amizades, a gente dança, a gente ri, a gente brinca" (Força).

"Na ginástica venho porque preciso. $\mathrm{Na}$ dança, venho porque gosto! Adoro dançar! Passar tempo, conversar, estar em grupo, de rir, fazer brincadeira" (Bondade). 
Na prática da DC pessoas idosas puderam experimentar um tempo de possibilidades para aprender coisas novas, aceitação dos erros e das limitações físicas, bem como a necessidade de adaptação. Como na DC não se exige performance, a ênfase não é na técnica e sim no desafio de cada um dar seu melhor. O novo é visto como algo possível, e o possível pode ser o suficiente.

"Dançar é uma novidade, pois eu nunca dancei na minha vida. Sei que não vou ser um bailarino, mas acho que estou indo bem. Traz assim uma novidade para vida, pois nunca fui de dançar, para mim está sendo um desafio, então o que eu já estou fazendo está bom de tamanho” (Fé).

Os participantes relacionaram as experiências vividas e compartilhadas com aspectos da vida que são ressignificados pela dança e pelo estar junto, o que estimula a autoestima e confiança para enfrentamento de novos desafios.

"Essa frase que sempre é dita na Roda, A dança é como nossa a vida, mesmo que a gente erre não pode parar, me marcou. Esse para mim é o significado da dança. Mesmo que erre não pare, pois a vida é assim mesmo. A gente tropeça, erra, mas vamos em frente. Levantar a cabeça e seguir" (Contentamento).

Ao exprimir em palavras as imagens que tinham da DC, as pessoas idosas retomaram o caráter coletivo demonstrando como essa prática possibilita a integração e socialização entre as pessoas. Percebese que os participantes, quando estão dançando, se distanciam das preocupações diárias, vivenciam o estar junto numa perspectiva de acolhimento e inteireza.

\footnotetext{
“O que vem na minha cabeça é união. Como vou te dizer, é uma dança que une as pessoas” (Perdão).

“O grupo! Está todo mundo junto tentando esquecer os problemas do dia a dia, pelo menos aqui tu esqueces se tem algum problema" (Fé).

"Eu penso no abraço, quando nos abraçamos no círculo no final, é muito bom!” (Apoio).
}

A DC possibilita o fortalecimento dos laços sociais, bem como a diminuição da sensação de solidão e isolamento que acomete muitos idosos. As pessoas idosas relataram que, se não estivessem na DC, provavelmente, estariam em casa, sozinhas ou sem ninguém para conversar.

"Eu sou muito só, moramos nós três (marido e filho), mas não tem ninguém para conversar, para dizer nada. Então na dança fiz outras amizades. Passei a interagir melhor com as outras pessoas" (Contentamento).

\section{Sentindo por meio da dança circular}

Por meio da DC a pessoa idosa vivencia o dançar junto, estar e pertencer a um grupo, sem, contudo, deixar de ser única. Percebe sua individualidade e a do outro que partilha e compartilha aquele momento. Para aprender os passos da dança precisa estar centrada em si, direcionando sua atenção para o momento vivido, buscando estratégias para lidar com fatores de dispersão.

"Eu tento ficar, não sei se tu nota, eu fico muito centrada para aprender os passos. Tem umas que falam mais, mas é do jeito delas e a gente tem que respeitar, cada um é um. Mas eu gosto de ficar centrada para aprender, eu gosto de aprender. Eu me sinto bem quando eu aprendo, quando eu estou acompanhando" (Confiança).

Cada participante descreve a experiência de dançar de maneira bastante particular, de acordo com suas percepções e sentimentos. Para algumas o fato de estarem de mãos dadas remete à sensação de segurança, como relatou esta idosa que em seu quotidiano fazia uso de muletas para deambular. Dar as mãos no círculo possibilitou que se sentisse segura para dançar, sendo apoiada e apoiando o grupo.

"Primeiro eu fiquei chateada em ter que andar de muleta, coisa chata. Mas agora eu não ligo mais. Tem que pensar que é para auxiliar e muleta é charme. O médico já disse que não posso ficar sem usar, um tombo para mim, Deus o livre! Pode ser um final de vida numa cadeira de rodas. $\mathrm{Na}$ dança, de mãos dadas, eu me sinto segura. Na hora do círculo eu não tenho dificuldade" (Propósito). 
Outros destacaram o prazer, a felicidade, a paz e outras sensações de bem-estar que a atividade lhes proporcionava.

"Eu me sinto muito bem quando estou dançando, me sinto bem à vontade. Faz bem para o físico, vou te dizer que faz. Mais é pelo prazer de dançar, pois eu gosto. É esse prazer que me dá" (Diversão).

"Cada vez que a gente vem dançar, digamos que é mais uma gotinha de otimismo plantada no coraçãozinho da gente" (Contentamento).

"Me sinto feliz. Apesar de errar um pouquinho. Mas não vejo o erro como problema, me sinto bem" (Equilíbrio).

Desse modo, as pessoas idosas trouxeram de seu imaginário, a partir da experiência de ser/estar junto dançando, que a DC como parte da vida quotidiana, é um espaço de trocas, de pertencimento, do viver coletivo ligado por laços emocionais e pelo afeto.

\section{DISCUSSÃO}

Este estudo possibilitou a compreensão da DC no quotidiano das pessoas idosas, sendo relevante para promover a melhoria da sua qualidade de vida. A DC permite a inclusão, a sensação de pertencimento e aproximação entre os pares, preservando a sua individualidade.

Os dados encontrados na categoria "Atribuindo Significado à Dança Circular" vão ao encontro aos resultados de um estudo que investigou os fatores psicológicos e emocionais de idosos praticantes de dança de salão. A prática de dança proporciona um contexto rico de interações sociais e experiências positivas $^{16}$.

Por meio desta prática integrativa, ocorre a vivência do retorno do arcaico em meio a uma sociedade marcada pela tecnologia e pelo saber científico, característicos da Pós-Modernidade, uma vez que remete os participantes às danças tribais. Favorece a transfiguração da era do "eu", para a era do "nós", pois é através do olhar do outro que eu me reconheço e me faço existiri"
O pensamento pós-moderno propõe o declínio do individualismo, de modo que o ser humano não pode ser analisado individualmente. Cada pessoa representa um papel dentro de uma tribo. O tribalismo traz a importância do sentimento de pertencimento a um lugar, a um grupo, como fundamento essencial de toda a vida social. A sociedade contemporânea é constituída por diversas tribos, que são caracterizadas pela fluidez, pelos ajuntamentos pontuais e pela dispersão. O tribalismo é um fenômeno cultural, "verdadeira revolução espiritual, revolução dos sentimentos que ressalta a alegria da vida primitiva, da vida nativa", em que as tribos urbanas revelam a urgência de uma socialidade empática onde ocorra partilha das emoções, partilha dos afetos ${ }^{18}$. É assim que compreendemos cada Roda como uma tribo, a(s) Tribo(s) da dança circular.

Ao mesmo tempo em que a ênfase no futuro dá lugar à importância do aqui e agora, o viver no presente mobiliza a energia societal, o instante se eterniza, tornando-se um lugar privilegiado do prazer de ser $^{19}$.

As rodas de DC foram descritas pelos participantes da pesquisa como sendo um ambiente onde as pessoas se fazem presentes umas com as outras, de forma lúdica e festiva se unem por laços de afeto e cultuam a ética da estética, que é este querer estar junto com, o cimento, o elo social, o experimentar junto algo como fator de socialização ${ }^{18}$. Corroborando com esses resultados, outros estudos identificaram que a empatia, a solidariedade e acolhimento permeiam as relações grupais proporcionando vínculo e sentimento de pertencimento entre os participantes ${ }^{19,20}$.

O ser humano sempre buscou estratégias para expressar seus sentimentos e emoções, e a dança, de uma forma geral, representa uma delas. A DC, ao proclamar simplicidade do ritmo e execução, pode ser trabalhada em grupo, compondo um círculo onde os participantes dançam juntos, buscando a integração na roda através do canto, ritmo e execução, a fim de promover o equilíbrio, bem-estar físico, mental e social ${ }^{21,22}$.

A DC pode ser considerada um fator de socialização que une aqueles que veem na dança uma possibilidade de constituir encontros e relações, que por meio do ritmo, da música e dos movimentos 
são colocados em sintonia com o círculo e com a ancestralidade de cada dança ${ }^{23}$. $\mathrm{Na}$ roda de DCa "forma" se faz presente a todo momento, sendo formante, porém não formal, possibilitando ver os contornos de dentro, aprendendo sobre o espaço do outro e o nosso espaço. As diversidades e diferenças deram forma à dança, sem que houvesse uma formalidade, favorecendo o acolher, amparar e conviver junto. Nesta perspectiva, um recurso metodológico que se apoie na forma é inteiramente pertinente, caso se pretenda dar conta de uma sociedade cada vez mais estruturada na imagem ${ }^{14}$.

Dançar em roda desencadeia uma nova ética diante da vida que possibilita a ressignificação de comportamentos e posturas para o encontro consigo e com o outro.

$\mathrm{Na}$ categoria "Sentindo através da Dança Circular", a prática da DC propõe a experiência coletiva do dançar junto que reconhece e convive com as diversidades ${ }^{24}$. No círculo, formado pelas mãos dadas, ninguém tem lugar de destaque, remetendo aos participantes a sensação de estarem incluídos no todo. Uma vez que todos os pontos de um círculo são pontos de retorno, percorrendo o círculo, girase 360 graus sem perder a relação com o centro, e cada ponto tem a mesma distância em relação ao centro ${ }^{7}$. Assim, simbolicamente compartilha um espaço de pertencimento, cooperação, segurança, solidariedade e unidade.

Por meio da DC, pode ocorrer o cuidado de saúde interconectado com as práticas de promoção da saúde. Atividades vistas não como exclusivamente para a prescrição de estilos saudáveis, mas como a criação de possibilidades, que podem contribuir para a emancipação dos indivíduos, grupos, comunidades e trabalhadores da saúde e transformar comportamento de vida ${ }^{25}$.

Laços afetivos construídos num ambiente de convívio e aprendizagem contribuem para com a percepção dos participantes em se tornarem pessoas mais felizes e ativas ${ }^{26}$. A oportunidade de estar junto possibilita amenizar o isolamento e a solidão, um dos mais graves problemas da população idosa, levando-os a (re) criar o sentimento de pertença a um grupo, a uma comunidade, renascendo para a vida sociocomunitária ${ }^{27}$.
A manutenção de relações sociais é importante para uma vida saudável, diminuindo o isolamento social e melhorando sua autopercepção. A participação em grupos estimula a pessoa idosa a se manter ativo diante a realização de atividades que contribuam para seu empoderamento ao valorizar sua individualidade e autonomia. É nesse contexto que se observa a interação do indivíduo, possibilitando, assim, uma maior inserção no grupo, como na dança circular, dando voz à pessoa idosa.

$\mathrm{Na}$ DC as relações dos participantes são horizontais, conferindo um caráter significativo coletivo e pessoal, em que aspectos positivos são vivenciados, tornando o sujeito mais resiliente ao enfrentamento do processo saúde-doença? 7 .

Dessa forma, além de ampliar a capacidade motora e postural, a DC recria a possibilidade para a reorganização do equilíbrio tanto interno como externo, expressando a gestualidade da vida, traduzindo sonhos e exercitando sentimentos e imaginação ${ }^{23}$. Além disso, o cuidado com o corpo, com a estética estimula o desenvolvimento da auto estima ${ }^{5}$. Trabalhar a beleza na velhice significa saúde e cuidado de si e cuidado com o corpo, com a imagem ${ }^{27}$.

Outro aspecto que se revelou a partir dos dados, refere-se aos benefícios biopsicossociais gerados pela dança na vida dos idosos verificou que a dança, ao ser praticada pelas pessoas idosas, gera sensações e sentimentos de bem-estar que contribuem com a melhoria da qualidade de vida dos idosos, bem como a promoção de uma vida mais saudável. Deste modo, propõe que oportunidades para a prática de dança, para essa faixa etária, sejam mais ofertadas por parte de órgãos de saúde pública ${ }^{28}$, destacando-se a sua inclusão em UBS que desenvolvem as práticas integrativas e complementares ${ }^{2}$.

A DC propicia aos participantes o despertar da consciência do corpo. A percepção de significados e satisfação com o envolvimento da dança promove o bem-estar entre indivíduos, traz benefícios físicos, sociais e emocionais, com melhora no relaxamento, prazer e controle do humor, deixando-os mais saudáveis ${ }^{17}$. A DC, atividade que inspira e motiva a expressão de sentimentos, possibilita o reencontro do ritmo interno ao homem ocidental, para que possa 
organizar e compreender o mundo, a realidade e o seu próprio ser, em constante transformação ${ }^{24}$.

A Pós-Modernidade pede outras qualidades humanas, enfrentamento das adversidades com abertura para a diversidade, complexidade para compreender e simplicidade para agir, colaboração e compartilhamento, em que a consideração dos afetos, do emocional, das paixões permite integrar as forças do imaginário no entendimento holístico que se pode ter do estar junto ${ }^{18,29}$.

Na perspectiva de Michel Maffesoli, o imaginário ultrapassa o indivíduo, é nutrido pelo coletivo, sendo um conjunto de construções mentais racionais e não racionais de impulsos para a ação, uma represa de sentimentos, emoções, valores, afeto, símbolos e imagens ${ }^{12}$.

Como limitações do estudo, percebe-se que a natureza local da realização da DC limita os dados encontrados sugerindo a sua ampliação para outros espaços, envolvendo o quotidiano, o imaginário e a sua articulação a demais PICs como práticas de promoção da saúde.

\section{CONCLUSÃO}

A Dança Circular, no imaginário da pessoa idosa, potencializa o estar junto, tem caráter acolhedor e inclusivo que favorece a sensação de pertencimento. As pessoas idosas que dançam exercitam a atenção, memória, cognição, expressão, além da socialização e diminuição do isolamento social e pertencimento comunitário. A principal contribuição deste estudo é possibilitar que pesquisadores, profissionais da saúde possam se apropriar dessa prática integrativa e complementar e estimular a sua realização em outros espaços.

O sentir junto se fez presente, onde sentimentos de felicidade, paz, contentamento, otimismo e prazer foram delineando a ressignificação do viver das pessoas idosas, tornando-as mais resilientes às adversidades do quotidiano e direcionadas a um viver mais saudável.

Ancorando-se na Sociologia Compreensiva de Michel Maffesoli, a Enfermagem pode compreender o ser humano de maneira holística, considerando aspectos não mensuráveis, como os significados e os sentimentos, o próprio imaginário, nas ações de cuidar. A compreensão do significado da DC no imaginário da pessoa idosa em seu quotidiano mostrou que essa atividade pode estar articulada com a razão sensível, integra o simbólico e o imaginário, e contribui como expressão da vida, sendo um espaço de trocas.

Diante disso, a DC pode ser utilizada pelo Enfermeiro e demais profissionais da saúde como mais um recurso disponível para o cuidado da população idosa com vistas à Promoção da Saúde. Finalmente, sugere-se que a prática da DC seja incentivada pelos profissionais da saúde em seu quotidiano.

Editado por: Maria Luiza Diniz de Sousa Lopes

\section{REFERÊNCIAS}

1. Borges EGS, Vale RGS, Pernambuco CS, Carder SA, Sa SPC, Miguel PF, et al. Effects of dance on the postural balance, cognition and functional autonomy of older adults. Rev Bras Enferm. 2018;71(Supl 5):2302-09. Disponível em: https://doi. org/10.1590/0034-7167-2017-0253 .

2. Dalmolin IS, Heidemann ITSB. Integrative and complementary practices in Primary Care: unveiling health promotion. Rev Latinoam Enferm. 2020;28:e3277. Disponível em: https://doi. org/10.1590/1518-8345.3162.3277.

3. Schneider AS, Ceolin S, Badke MR, Heisler EV, Lautenschleger G, da Costa AR. Applicability and benefits of dance therapy as a health care practice: an integrative review. Res Soc Develop 2020;9(7):e344974009. Disponível em: https://doi. org/10.33448/rsd-v9i7.4009 .

4. Sousa IMCD, Tesser CD. Traditional and complementary medicine in Brazil: inclusion in the Brazilian Unified National Health System and integration with primary care. Cad Saúde Pública. 2017;33(1):1-15. Disponível em: http://doi. org/10.1590/0102-311X00150215. 
5. Carvalho FFB, Nogueira JAD. Práticas corporais e atividades físicas na perspectiva da Promoção da Saúde na Atenção Básica. Ciênc Saúde Colet. 2016;21(6):1829-38. Disponível em: https://doi. org/10.1590/1413-81232015216.07482016.

6. Sousa LA, Barro NF. Integrative and Complementary Practices in the Unified Health System: progresses and challenges. Rev Latinoam Enferm. 2018;26:e3041. Disponível em: https://doi. org/10.1590/1518-8345.2854.3041.

7. Azevedo C, Moura CC, Corrêa HP, Mata LRF, Chaves ECL, Chianca TCM. Complementary and integrative therapies in the scope of nursing: legal aspects and academic-assistance panorama. Esc Anna Nery Rev. Enferm. 2019;23(2):e20180389. Disponível em: https://doi.org/10.1590/2177-9465ean-2018-0389 .

8. Malta DC, Reis AAC, Jaime PC, Neto OLM, Silva MMA, Akerman M. Brazil's Unified Health System and the National Health Promotion Policy: prospects, results, progress and challenges in times of crisis. Ciênc Saúde Colet. 2018;23(6):1799-809. Disponível em: https://doi.org/10.1590/1413-81232018236.04782018 .

9. Heidemann ITSB, Cypriano CC, Gastaldo D, Jackson S, Rocha CG, Fagundes E. A comparative study of primary care health promotion practices in Florianópolis, Santa Catarina State, Brazil, and Toronto, Ontario, Canada. Cad Saúde Pública. 2018;34(4):1799-809. Disponível em: https://doi. org/10.1590/0102-311X00214516 .

10. Labegalini CMG, Sescon NI, Hammerschmidt KSA, Jaques AE, Carreira L, Baldissera VDA. Educational and care-related dialogical pathway on active aging with family health strategy professionals. Texto \& Contexto Enferm. 2020;29:e20180235. Disponível em: https://doi.org/10.1590/1980-265XTCE-2018-0235

11. Silva KM, Nitchske RG, Santos SMA. The dance and the aging: benefits described in the literature. Cienc Cuid Saúde. 2018;17(3):1-10. Disponível em: https:// doi.org/10.4025/cienccuidsaude.v17i3.39020 .

12. Nistchke RG, Tholl AD, Potrich T, Silva K M, Michelin SR, Laureano DD. Contributions of Michel Maffesoli thinking to research in nursing and health. Texto \& Contexto Enferm. 2017;26(4):112. Disponível em: https://doi.org/10.1590/010407072017003230017 .

13. Costa JC, Nitschke RG, Thol AD, Henckemaier L, Michelin SR, Silva APM. Imaginary of family health promotion: family's look in the everyday life of Primary Care. Ciênc Cuid Saúde. 2017;16(1):10511. Disponível em: http://dx.doi.org/10.4025/ cienccuidsaude.v16i1.33006 .
14. Schatzman L, Strauss AL. Field research: strategies for a natural sociology. New Jersey: Printice-Hall; 1973.

15. Brasil. Ministério da Saúde. Resolução no 466, de 12 de dezembro de 2012. Normaliza a pesquisa em seres humanos. Brasília, DF: Conselho Nacional de Saúde; 2012. Disponível em: http://conselho.saude.gov.br/ resolucoes/2012/Reso466.pdf

16. Oliveira DV, Favero PF, Codonhato R, Moreira CR, Antunes MD, do Nascimento Jr. JRA. Investigação dos fatores psicológicos e emocionais de idosos frequentadores de clubes de dança de salão. Rev Bras Geriatr Gerontol. 2017. 20(6):802-10. Disponível em: https://doi.org/10.1590/1981-22562017020.170089 .

17. Brito RMM, Germano IMP, Severo Jr. R. Dança e movimento como processos terapêuticos: contextualização histórica e comparação entre diferentes vertentes. Hist Ciênc Saúde-Manguinhos. 2021;28(1):146-65. Disponível em: https://doi. org/10.1590/S0104-59702021000100008 .

18. Mafessoli M. O tempo das tribos: o declínio do individualismo nas sociedades de massa. $5^{\mathrm{a}}$ ed. Rio de Janeiro: Forense; 2014.

19. Friedrich TL, Petermann XB, Miolo SB, Pivetta HMF. Motivações para práticas coletivas na Atenção Básica: percepção de usuários e profissionais. Interface. 2018;22(65):373-85. Disponível em: https://doi.org/10.1590/1807-57622016.0833 .

20. Nogueira ALG, Munari DB, Fortuna CM, Santos LF. Pistas para potencializar grupos na Atenção Primária à Saúde. Rev Bras Enferm. 2016;69(5):96471. Disponível em: https://doi.org/10.1590/00347167-2015-0102.

21. Maffesoli M. Pactos emocionais: reflexões em torno da moral, da ética e da deontologia. Curitiba: PUCPRESS; 2018.

22. Santos ERS, Mendonça GA, Souza ZCSN, Morais AC, Novaes AL. Dança circular em maternidade: vivência extensionista. Rev Bras Extensão Univ. 2021;12(1):23-32. Disponível em: https://doi. org/10.36661/2358-0399.2021v12i01.11632

23. Farias J, Marinho A. Lúdico e danças circulares: reflexões sobre um grupo em um centro de saúde de Florianópolis (SC). Rev Bras Educ Fís Esp. 2019;33(1):61-70. Disponível em: https://doi. org/10.11606/issn.1981-4690.v33i1p61-70 .

24. Borges RM, Brito CMD, Monteiro CF. Health, leisure, and aging: an analysis of Meninas de Sinhá's circle game. Interface (Botucatu). 2020;24:e190279. Disponível em: http://dx.doi.org/10.1590/ interface.190279. 
25. Silva SMM, Grando BS. In the bodies of dance: intercultural education and teacher training. Rev Educ Pública. 2017;26(62):527-48. Disponível em: http://periodicoscientificos.ufmt.br/ojs/index.php/ educacaopublica/article/view/5497.

26. Carvalho FFB, Cohen SC, Akerman M. Reflecting on the established in Health Promotion to problematize' dogmas'. Saúde Debate. 2017;41(3):265-76. Disponível em: http://doi.org/10.1590/0103-11042017S320 .

27. Lange CH, Heidemann ITSB, Castro DSP, Pinto AH, Peters CW, Durand MK. Promoting the autonomy of rural older adults in active aging. Rev Bras Enferm. 2018;71(5):2411-7. Disponível em: https://doi. org/10.1590/0034-7167-2017-0570.
28. Fin TC, Rodrigues MP, Scortegagna SA. Old age and physical beauty among elderly women: a conversation between women. Rev Bras Geriatr Gerontol. 2017;20(1):77-87. Disponível em: https:// doi.org/10.1590/1981-22562017020.150096.

29. Fontoura LC, Bolzan RS, Azambuja AS, Abaid JLW, Smeha LN. Dancing on the third age: biopsychosocial benefits in the life of the elderly. Rev Eletrônica Discipl Sci. 2016;17(1):75-81. Disponível em: https:// periodicos.ufn.edu.br/index.php/disciplinarumCH/ article/view/2020/1868 . 